\title{
Research and Overview on Discipline Construction of Fitness-oriented Sport
}

\author{
Guoming Zhang \\ Wushu Department \\ School of Physical Education \\ Huanghe Science and Technology College \\ Zhengzhou, China
}

\begin{abstract}
With continuous improvement of the living standard, people's consciousness of body building and health keeping strengthens increasingly. Fitness oriented sport plays an active role in guiding people to grasp the scientific knowledge of health keeping and keep in good health properly. It has important realistic significance in promoting the integrated and continuous development of fitness oriented sport and spreading the scientific knowledge of body building and health keeping. This paper uses research methods like literature material law, expert interview method and logic analysis method, explaining the nature of health keeping and analyzing the development status of fitness oriented sport discipline. According to the relation between the sports science and the health keeping science, it has researched the subject status of sports in health keeping and the subject boundary of health keeping in sports, and the fitness oriented sport, the heath keeping sports and proposed the idea of building subject system of the fitness oriented sport, looking forward to providing theoretical reference basis for the in-depth and systematic research on fitness oriented sport.
\end{abstract}

Keywords-sport; health keeping; fitness oriented sport; discipline construction

\section{INTRODUCTION}

With the rapid development of social economy, people's living standard has been improved greatly. However, the everincreasing pressure from life, work and learning has had adverse effect on people's physical and psychological health, influencing living quality. More and more people increasingly realize the importance of fitness and begin to learn about the body building and health keeping through the internet, bookstore and library, television and media as well as the lecture, making health keeping become popular "burgeoning subject". According to the retrieve data on CNKI, in the past 35 years, namely from 1981 to 2015 , the paper concerned with "body building" yearly has increased from 155 to 46,304, and the paper concerned with "health keeping" has increased from 458 to 43,589. After entering the 21st century, academic circles have researched on body building and health keeping. In recent ten years, several tens of thousands of research results have appeared yearly. On one hand, it promotes the physical and psychological health of the masses; on the other hand, it has become a hot subject in the academic circles. Further construction of the fitness oriented sport will help to research the body building and health keeping more deeply and roundly, correctly grasp its nature and law, promoting people to grasp the scientific knowledge and skills in body building and health keeping.

\section{NATURE OF HEALTH KeEPING}

\section{A. Connotation of Health Keeping}

"Yang Sheng" derives from Guanzi · Jie, "The taste means the maintenance in life; the likes and dislikes toward pleasure, anger, sorrow and joy mean the change of life." [1] Yang refers to the maintenance and nourishment; Sheng refers to the life, including two aspects, the first is life itself and the second is the life course; health keeping means keeping fit, invigorating health effectively and maintaining the balance of activity of life through many ways, so as to prolong life. With a history of more than 2,000 years, health keeping has absorbed the essence of traditional philosophical culture and developed in Buddhism, Taoism and medical science, Confucianism and martial art, accumulating solid theoretical basis and culture of health keeping with eastern civilization features.

\section{B. The Difference between Body Building and Health Keeping}

The main purpose, content, theoretical basis and representation form of body building and health keeping are different, but it seems like no big differences exist between them. Therefore, it has become an important premise and guarantee to correctly research on the fitness oriented sport through further analyzing the relation between body building and health keeping.

As shown in "Table I", body building means taking exercises through the sport equipment and the specific methods, in order to invigorate health effectively, improve body function and cultivate taste; health keeping means using various means to take good care of health and prolong life. The theoretical basis of body building includes modern knowledge like human biology and humanistic and social science, while the theoretical basis of health keeping includes traditional philosophy and traditional Chinese medicine. Body building promotes the development of the physical and psychological health through sports. Except for the sports, the health keeping 
improves physical and psychological health and body function through traditional Chinese medicine, the environment, climate and diet; both body building and health keeping relates to physical and psychological health. However, the body building emphasizes "fitness", improving the function of body system and then promoting the more healthy and coordinating mind and body through sports. Health keeping stresses "preservation", taking good care of the health and prolonging life furthest. The whole life of people needs to go through the birth, growth, maturity, oldness and death. During the process, the energy of human body consumes till death. Dying without any illness is the ideal of people, but many people often get sick and have accidents for many reasons, which influence the quality of life, accelerate the energy consumption of human body and make life end in advance. Body building adjusts the metabolic rate, improves the function of body system and promotes the normal operation of the body through physical exercise. Meanwhile, it will also speed up the energy consumption and the aging of human body and then shorten lifespan. With a history of thousands of years, the health keeping has become an all-around operating means involving the traditional Chinese medicine, diet and daily life, traditional sports and environment, climate as well as custom. According to the theory on the health keeping in ancient times, the shape, Qi and spirit are footstones of the activity of life. The integration of the shape and Shen contributes to the longevity. The substance forming body is called "Jing" by the ancients. It is divided into the inborn Jing and the acquired Jing. The former comes from parents when the new life is born; the latter produces in the diet. The substance that makes people energetic and promotes the activity of human body is called "Qi" by the ancients. It is divided into the inborn Qi and the acquired Qi. The former is the driving force to promote the activity of life; the latter comes from the breath and diet and distributes in the tissues and organs. The ancients think the "spirit" dominates activity of human life and control the functional activity of human body. It consists of the inborn primordial spirit and the acquired spirit. The former belongs to the instinctive automatic adjusting function of the human body; the latter refers to the random control function involving the emotion, desire and thought of people. [2] Health keeping maintains the inborn primordial Jing, Qi and spirit through various means under the control of the acquired spirit, to make it consume as slow as possible. Meanwhile, it supplements the primordial Jing, Qi and spirit by the acquired Jing and Qi to maintain the balanced state of body metabolism and prolong life.

TABLE I. COMPARATIVE ANALYSIS OF Body BUILDING AND HEALTH KEEPING

\begin{tabular}{|l|l|l|l|l|}
\hline Concept & \multicolumn{1}{|c|}{$\begin{array}{c}\text { Main } \\
\text { purpose }\end{array}$} & \multicolumn{1}{|c|}{ Contents } & $\begin{array}{l}\text { Theoreti } \\
\text { cal basis }\end{array}$ & $\begin{array}{c}\text { Represent } \\
\text { ation } \\
\text { form }\end{array}$ \\
\hline $\begin{array}{l}\text { Body } \\
\text { building }\end{array}$ & $\begin{array}{l}\text { Invigorate } \\
\text { health } \\
\text { effectively }\end{array}$ & Physical exercise & $\begin{array}{l}\text { Modern } \\
\text { sports } \\
\text { theory }\end{array}$ & Fitness \\
\hline $\begin{array}{l}\text { Health } \\
\text { keeping }\end{array}$ & $\begin{array}{l}\text { Ensure } \\
\text { good } \\
\text { health and } \\
\text { long life }\end{array}$ & $\begin{array}{l}\text { Physical exercise, } \\
\text { traditional Chinese } \\
\text { medicine, } \\
\text { environment climate } \\
\text { and diet }\end{array}$ & $\begin{array}{l}\text { Theory of } \\
\text { traditiona } \\
1 \text { culture }\end{array}$ & $\begin{array}{l}\text { Preservati } \\
\text { on }\end{array}$ \\
\hline
\end{tabular}

\section{THE DisCIPLINE DEVELOPMENT STATUS OF FITNESS ORIENTED SPORT}

In the long history, people have explored the secret of health and longevity and have formed a unique culture of health keeping. With the development of the time, nowadays the masses are fascinated with health keeping, which has become popular. People want to add "health keeping" to everything. Evidently, the concept and the consciousness of health keeping have enjoyed popular support. However, few people can actually understand health keeping, so it is in urgent need of popularizing knowledge about it. At present, although with a long history, as a comprehensive discipline, the fitness oriented sport is in the initial stage of construction. According to the Undergraduate Specialty Catalogue of Higher Institutions [3] issued in 2012, the subsidiary discipline of traditional fitness oriented sport is set in the first-level discipline, the sports science. The traditional fitness oriented sport belongs to the third-level discipline of the sports science and attaches to the second-level discipline, martial arts and traditional national sports. The traditional fitness oriented sport and martial arts as well as the national folk sports form the third-level discipline of martial arts and the traditional national sport.

\section{ELEMENTS OF THE FITNESS ORIENTED SPORT}

\section{A. The Relation between the Sports Science and the Health Keeping Science}

As the first-level discipline, the sports science covers extensive contents of sports. According to different purposes, it can be divided into the competitive sports for competition, the military sports to improve war power, the body building sports to invigorate health effectively, the leisure sports for entertainment and the health keeping sports to ward off disease and prolong life. As a comprehensive discipline, the health keeping science has rich contents involving the traditional Chinese medicine and the sports. The contents related to sports have developed into a mature theoretical system of fitness oriented sport. Although the sports science and the health keeping science have covered unique contents respectively, the overlapped research contents have been formed in the development. That is to say, the contents of health keeping are included in the sports science, and the contents of sports are also included in health keeping science, so that the basis is provided to research the same contents. However, the researches on the common points are not identical. The sports science explores the law and feature of the health keeping sports from the perspective of sports, while the health keeping science researches the function of fitness oriented sport from the perspective of health keeping.

\section{B. The Status of Sports in the Discipline of Health Keeping Science}

As an important means of health keeping, the physical exercise plays a significant and irreplaceable role in the health keeping science. Systematic theory and practice systems have been formed by people advocating the health keeping in the past dynasties. It is not only the responsibility of the sports science but also the research category of health keeping 
science to excavate and arrange the knowledge of health keeping related to the physical exercise and do corresponding researches. Determination on status of sports in the health keeping science will help the scientific development of sports. Although the health keeping science covers many disciplines, the application of fitness oriented sports in the health keeping practice is very general. It has abundant application means suitable for different people. Moreover, the subjective initiative of people can be stimulated to participate in the health keep activities. In the fitness oriented sport, the exercisers can affect the body function through self-exercise and self-control and adjust the process of exercise according to the real experience. The change from passive to active mental state can have a more positive effect on the psychology of people, improve the dominant position of people and further stimulate their enthusiasm in health keeping. It shows the sports play a unique and irreplaceable role in health keeping science.

\section{The Definition of Health Keeping in the Sports Discipline}

The Undergraduate Specialty Catalogue of Higher Institutions issued in 2012 categorizes the traditional fitness oriented sport in the sports discipline. In reality, the health keeping uses the name of other disciplines like the fitness oriented sports and the guide to health keeping. In the concepts, the health keeping is the subject, the traditional sports, sports and the guide are attributes to modify and limit the subject. The subject decides the scope of the discipline, and the attribute decides the research direction. Obviously, these concepts all discuss the value of physical exercise in the health keeping. However, the traditional sports and sports cover many sports items, some of which, especially modern western sports have different fitness ideas from the traditional Chinese health keeping ideas, not suitable for health keeping. The guide covers a wide range but cannot cover all sports items related to health keeping. The expansion or shrinkage of research scope will result in unclear positioning of the research on the fitness oriented sport and influence the effect of research. Therefore, according to the criteria and principle of discipline classification, the "health keeping sports" in the sports discipline should be taken as the research object of the fitness oriented sport, to define the research scope of health keeping in the sports science. In the concept of "health keeping sports", the health keeping is the subject to limit the content of sports, indicating the research direction of health keeping sports relates to the health keeping, so that the research of fitness oriented sport can be conducted accurately.

\section{Research and Analysis on the Fitness Oriented Sport and the Health Keeping Sports}

Although the fitness oriented sport and the health keeping sport belong to health keeping science and sports science respectively, according to the classification criterion of the Undergraduate Specialty Catalogue of Higher Institutions issued in 2012, both of them belong to the research category of the sports science. Therefore, a physical educator researching health keeping should use the modern sports theory to research the theory and skill of the health keeping sport from the perspective of the sports science, and use the traditional theory of health keeping to explore the nature and law of the fitness oriented sport in warding off disease and prolonging life from the perspective of the health keeping science. The scientific development of discipline construction can be further promoted only through correctly regarding the relation between the sports and the health keeping and researching the problems of them from the correct perspectives. As the second-level discipline of health keeping science, the fitness oriented sport mainly researches the health keeping mechanism of different physical exercises. Therefore, it is necessary to research on the health keeping sports. Health keeping sports mainly research the law and features of physical activities good for health keeping, so that it should depend on the theory of fitness oriented sport to research. The application value of sports and health keeping can be excavated to continuously enrich the contents of the sports science and the health keeping science, improve the structure and promote the comprehensive development.

\section{DISCIPLINE S YSTEM CONSTRUCTION OF THE FITNESS ORIENTED SPORT}

As the second-level discipline of health keeping science, in fitness oriented sport, the application of physical exercises is researched in health keeping. Therefore, its discipline system should be constructed in accordance with the features and the discipline classification standard of sports science. According to the time sequence structure, the sports can be divided into the traditional sports and the modern sports. Based on the principle of discipline classification, the next level discipline of fitness oriented sport can be divided into the traditional and the modern fitness oriented sport (as shown in "Fig. 1"), and then making the fitness oriented sport into a systematic discipline system. The traditional fitness oriented sport researches the traditional theories and skills of the fitness oriented sport, develops the classical theories of health keeping; on the basis of the traditional theories of fitness oriented sport, the modern fitness oriented sport researches the theories and skills of fitness oriented sport integrating the modern sports thought, carries out the innovative development on the basis of inheriting the traditional thought on the fitness oriented sport and researches the future development of fitness oriented sport, with strong forward looking, reflecting the frontier trends of researches on fitness oriented sport.

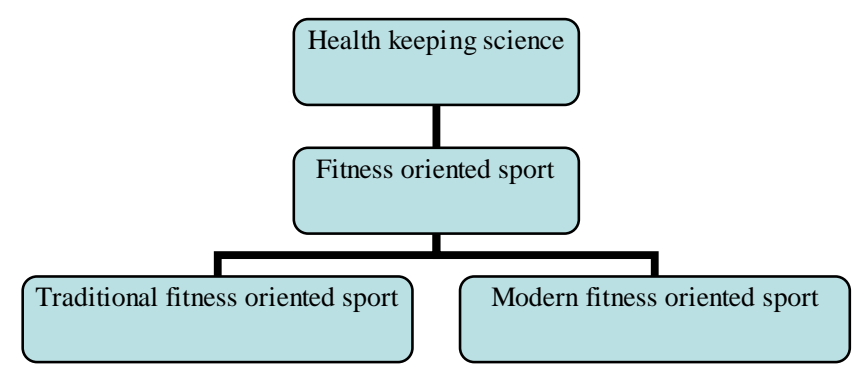

Fig. 1. Discipline system of the fitness oriented sport

\section{CONCLUSION}

The fitness oriented sport has a long history in our country with rich contents and a wide coverage. On the basis of 
traditional Chinese culture, it has deep and extensive influence, becoming one of the representatives of Chinese culture. In nowadays society, it will have a positive practical significance in inheriting and carrying forward the excellent health keeping culture and promoting the healthy development in mind and body through further strengthening the discipline construction of fitness oriented sport and continuously improving the discipline structure of it.

\section{ACKNOWLEDGEMENT}

In the process of writing this paper, I have received guidance from the teacher Yang Bailong and the teacher $\mathrm{Hu}$ Xiaofei and the help from my classmate Xu Haipeng. Here I express my heartfelt thanks to them. This paper cannot be finished without their support.

\section{REFERENCES}

[1] Chen Deping, Yao Chunpeng, Yao Dan. Research on the Health Keeping Idea in Guanzi [J], Guanzi Journal, March 2011: 5-10.

[2] Liu Tianjun. Chinese Medical Qigong [M], Beijing: China Press of Traditional Chinese Medicine, 2005.

[3] The Ministry of Education of the People's Republic of China, notice of the Ministry of Education on printing and distributing the documents of Undergraduate Specialty Catalogue of Higher Institutions (2012) and the Administration of the Undergraduate Specialty Setting of Regular Institutions of Higher Education
[EB/OL], http://www.moe.gov.cn/srcsite/A08/moe_1034/s3882/201209/t2012091 8_143152.html,2012-09-18/2016-11-05.

[4] Academic Degrees Committee of the State Council, notice of the Ministry of Education on printing and distributing the Discipline Catalogue Setting and Management of Degree Awarding and Talent Training,

[EB/OL].http://www.moe.gov.cn/s78/A22/xwb_left/moe_833/moe_834 /tnull_45419.html,2009-2-25/2016-11-05.

[5] Zheng Wen. Discussion on Subject Nature and Research Category of Chinese Health Keeping Science [J], Journal of Traditional Chinese Medicine Management, 2012, (06): 505-507.

[6] Ni Yike, Shao Xiaojun, Zhang Zizhi. Theoretical Basis of Discipline Construction of Traditional National Sports Science [J], Sports Science, 2005, 01: 56-60

[7] Huang Lu. An Overview and Prospect of Interdisciplinary Research in Sports Science [J], Journal of Chengdu Sport University, 2012, 02: 2832.

[8] Li Rong. The Idea of Establishing Second-level Discipline of Health Keeping Science-and Discussion on the Property and Category of Health Keeping and Its Related Discipline [J], Traditional Chinese Medical Education, 2000, 04:56.

[9] Gao Heyong. Research on Systematic Frame of Fitness Oriented Sport [D], Guangzhou Sport University, 2008. 